\title{
Seismic Design of Base-Isolated Buildings in Mexico. Part 1: Guidelines of a Model Code
}

\author{
Arturo Tena-Colunga*
}

Departamento de Materiales, Universidad Autónoma Metropolitana

\begin{abstract}
The updated version for the Manual of Civil Structures (MOC), a model seismic code in Mexico, was published in 2008. MOC also is incorporating guidelines for the seismic design of base-isolated structures this year 2012, being the first Mexican code to include such recommendations. This paper summarizes the most relevant aspects of these guidelines, their relations to other guidelines worldwide and research efforts conducted in Mexico and worldwide to improve the seismic design of base-isolated structures.
\end{abstract}

Keywords: Base isolated structures, design guidelines, seismic codes.

\section{INTRODUCTION}

The Manual of Civil Structures (MOC), one of the model design codes in Mexico, was updated. This manual is frequently used in the entire nation in lieu of a specific code for a state or a city. The new version for this manual and all its chapters was published in $2008[1,2]$. Among the new planned chapters, there is one devoted to the seismic design of base-isolated structures, which is going to be published in 2012 [3].

The guidelines for base isolation are based on a previous proposal that took care to make them compatible with the design philosophy of the seismic codes of Mexico and that included the seismic risk and hazard of Mexico, to ease their incorporation into model seismic codes of Mexico [4,5]. However, additional material has been reviewed, adapted and/or included, so the guidelines for base-isolated structures in MOC are a much improved version compared to the previous proposal.

Some of the most important provisions that impacted the seismic design of base isolated structures are summarized in the following sections. The bases and design philosophy of previous and current seismic design provisions of MOC code in English can be found elsewhere [2,6].

\section{GENERAL DESIGN CRITERIA}

The seismic design of base-isolated structures should satisfy two limit states according to the proposed guidelines [3]:

- serviceability limit state, where deformations should be restricted to prevent damage and warrant that the isolation system is activated and,

\footnotetext{
*Address correspondence to this author at the Departamento de Materiales, Universidad Autónoma Metropolitana; Tel: + (52-55) 5318-9460; Fax: +(52-55) 5318-9085; E-mail:atc@correo.azc.uam.mx
}

- collapse prevention limit state, where the strength and the deformation capacity of the isolation system and structural elements (below, above and within the isolation interface) should be assessed to verify that they can withstand the applied forces and accommodate the deformation demands due to the maximum credible earthquake (MCE). The structure above the isolation system should remain essentially elastic or experience very limited damage. This condition should be verified by checking against the allowable interstory drifts, as specified in section "review of limit states".

Base-isolated structures should be designed considering the action of three simultaneous orthogonal components for the ground motions (two horizontal and one vertical) and their combinations with other general loading conditions (i.e., gravitational) specified by the manual.

The stability of the isolation system for lateral and gravitational load combinations should be reviewed both analytically and experimentally based on test data at the design displacement $\left(D_{T}\right)$.

Base-isolated structures should be built in near-firm to rock soil profile types. This must be verified in terms of what it is defined in MOC-2008 as the site factor, $F_{s}$, and the site period, $T_{s}$, as explained elsewhere [1]. The proposed ranges are: $1.0 \leq F_{s} \leq 1.4$ and $0 \leq T_{s} \leq 0.7$. Alternatively, the soil profile type could be assessed in terms of: (a) the shear wave velocity, that for the soils under consideration, should be $v_{s} \geq 180 \mathrm{~m} / \mathrm{s}$ and/or, (b) the number of hits for the standard penetration test, which for the soils under consideration should be equal or greater than $30\left(N_{P E} \geq 30\right)$.

The recommendation to use base isolation systems in competent soil profile types is justified. The advantages of using base isolation in firm soils or rocks are well-known. The disadvantages of using base isolation in soft soils be- 
cause of the likeliness of resonant responses and instability of the isolation system have also been well documented [7, 8]. In addition, potential problems because of uneven soil settlements may be triggered in soft soils for many foundations that are not fully supported in the firm strata.

Height limits are specified for the most common structural systems used in buildings and addressed by the code. The proposed height limits are based on the base-isolation guidelines of the United States [9,10], but they were adapted to Mexican design conditions [i.e., 5]. However, a window is open in MOC [3] for special base-isolated structures that may surpass the limiting height values. Taller base-isolated buildings could be built only if a group of experts independent from the original design team (peer-review committee) authorizes such projects.

It is also established in MOC [3] that if the structure above the isolation system contains special elements such as passive energy dissipators or dampers, their design should also meet the criteria established for such devices within the Manual and that the proposed design values for effective damping and the seismic reduction factor should be fully justified. This statement is included as it is recognized that such mixed systems are becoming more commonly used worldwide today, so guidelines should be set for a coherent seismic design.

\section{ELASTIC DESIGN SPECTRA}

As described in further detail elsewhere [2], the elastic acceleration design spectra for MOC code is, in theory, an infinite number of discrete functions within the Mexican Territory, as a direct consequence of taking the decision of defining the seismic hazard as a continuous function.

The proposed elastic acceleration design spectra are transparent in essence, as modification factors are defined exclusively in terms of the seismic hazard and site effects.

For the maximum credible earthquake (MCE), the elastic acceleration design spectrum for $5 \%$ equivalent viscous damping for structures of the group B (standard occupancy) for MOC-2008 code [1,2], schematically depicted in Fig. (1), is defined with the following general expressions:

$$
a=\frac{S_{a}\left(T_{a s}\right)}{g}=\left\{\begin{array}{lll}
\mathrm{a}_{0}+\left(\beta c-\mathrm{a}_{0}\right) \frac{\mathrm{T}_{\mathrm{as}}}{\mathrm{T}_{\mathrm{a}}} ; & \text { if } & \mathrm{T}_{\mathrm{as}}<\mathrm{T}_{\mathrm{a}} \\
\beta \mathrm{c} ; & \text { if } & \mathrm{T}_{\mathrm{a}} \leq \mathrm{T}_{\mathrm{as}}<\mathrm{T}_{\mathrm{b}} \\
\beta \mathrm{c}\left(\frac{\mathrm{T}_{\mathrm{b}}}{\mathrm{T}_{\mathrm{a}}}\right)^{\mathrm{r}} ; & \text { if } & \mathrm{T}_{\mathrm{b}} \leq \mathrm{T}_{\mathrm{as}}<\mathrm{T}_{\mathrm{c}} \\
\beta \mathrm{c}\left(\frac{T_{b}}{T_{c}}\right)^{r}\left[\mathrm{k}+(1-\mathrm{k})\left(\frac{\mathrm{T}_{\mathrm{c}}}{\mathrm{T}_{\mathrm{as}}}\right)^{2}\right]\left(\frac{\mathrm{T}_{\mathrm{c}}}{\mathrm{T}_{a s}}\right)^{2} ; & \text { if } & \mathrm{T}_{\mathrm{as}} \geq \mathrm{T}_{\mathrm{c}}
\end{array}\right.
$$

where $a$ is the spectral acceleration ordinate for the design spectrum $\left(S_{a}\right)$ expressed as a fraction of the acceleration of gravity $(g), a_{0}$ is the ground acceleration coefficient, $c$ is the seismic coefficient that defines the plateau, $T_{a s}$ is the effective natural period for the base-isolated structure, $T_{a}$ and $T_{b}$ are control periods that define the plateau of the spectrum, $T_{c}$ is a control period that defines the descending branch of the acceleration spectrum so that the displacement design spectrum computed from the acceleration design spectrum will converge to the ground displacement at long periods, $r$ is the parameter that defines the descending branch of the acceleration spectrum in the period range $T_{b} \leq T_{a s}<T_{c}, k$ is the parameter that defines the descending branch of the acceleration spectrum when $T_{a s} \geq T_{c}$ and $\beta$ is a damping factor. The control period $T_{c}$ and the parameters $r$ and $k$ that define the descending branch of the acceleration spectrum are defined as follows:

$$
\begin{aligned}
& T_{c}= \begin{cases}3 s & \text { if } T_{b}<3 s \\
T_{b} & \text { if } T_{b} \geq 3 s\end{cases} \\
& r=T_{s} ; \quad 0.5 \leq r \leq 1.0 \\
& k=\left\{\begin{array}{cl}
\min \left\{1.5,2-T_{s}\right\} & \text { if } T_{s} \leq 1.65 s \\
\max \left\{0.35, \beta / F_{r}\right\} & \text { if } T_{s}>1.65 s
\end{array}\right.
\end{aligned}
$$

where $T_{s}$ is the site period and all remaining terms have been already defined.

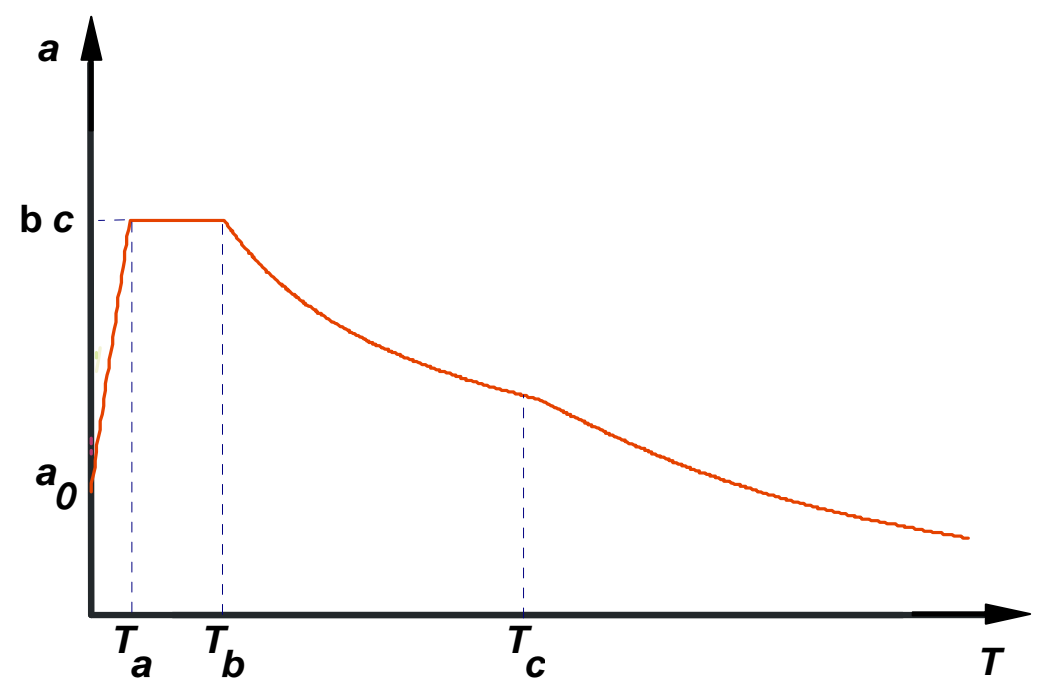

Fig. (1). Schematic representation of elastic acceleration design spectra for MOC-2008. 
The damping factor $\beta$ allows to modify the spectral ordinates for damping ratios different from $5 \%$ to account only for the potential supplemental damping of the isolation system, and it is defined by the following expressions:

$$
\beta=\left(\frac{0.05}{\zeta_{\mathrm{as}}}\right)^{\lambda} \text { where } \lambda=\left\{\begin{array}{ll}
0.45 & \text { if } \mathrm{T}_{\mathrm{as}}<\mathrm{T}_{\mathrm{c}} \\
0.45\left(\frac{\mathrm{T}_{\mathrm{as}}}{\mathrm{T}_{\mathrm{c}}}\right) & \text { if } \mathrm{T}_{\mathrm{as}} \geq \mathrm{T}_{\mathrm{c}}
\end{array}\right\}
$$

where $\zeta_{a s}$ is the equivalent effective damping provided by the isolation system at the design displacement. This proposal is based on a study conducted for structural systems with a linear response [11], although there are other interesting proposals available in the literature [12-16].

Displacement design spectra $S_{d}\left(T_{a s}\right)$ is obtained indirectly from acceleration design spectra based upon a standard relation from structural dynamics:

$S_{d}\left(T_{a s}\right)=\left(\frac{T_{a s}}{2 \pi}\right)^{2} S_{a}\left(T_{a s}\right)$

Typical acceleration and displacement spectra for the design of base-isolated structures for effective damping ratios from 5 to 20 percent are depicted in Figs. (2 and 3). The site profile type is similar to the one defined in former MOC-93 code for zone D-I [6].

As it is demonstrated elsewhere $[1,2]$, when the period $T \rightarrow \infty$, the maximum spectral displacement converges to the peak ground displacement $D_{\max }$. This fact is an important improvement in MOC-2008 with respect to its previous version of 1993 and with respect to most international codes, where due to the definition of the descending branch of the acceleration spectra for long periods, displacements grew up irrationally for long periods, as illustrated in Fig. (4) and previously discussed in the literature $[4,17]$.

Different proposals for the displacement design spectra for zone D-I of previous MOC-93 code are compared in Fig. (4). It can be observed that displacements grew up irrationally under MOC-93 code. Current MOC-2008 proposal takes care of that problem, as for long periods, defined curves converge to the ground displacement. The guidelines proposed by Tena-Colunga $[4,5]$ also converge to the ground displacement. In fact, there is a reasonable correlation in what was proposed by Tena-Colunga [4] and what it is now proposed in MOC for this site $[1,3]$, particularly in the pe-

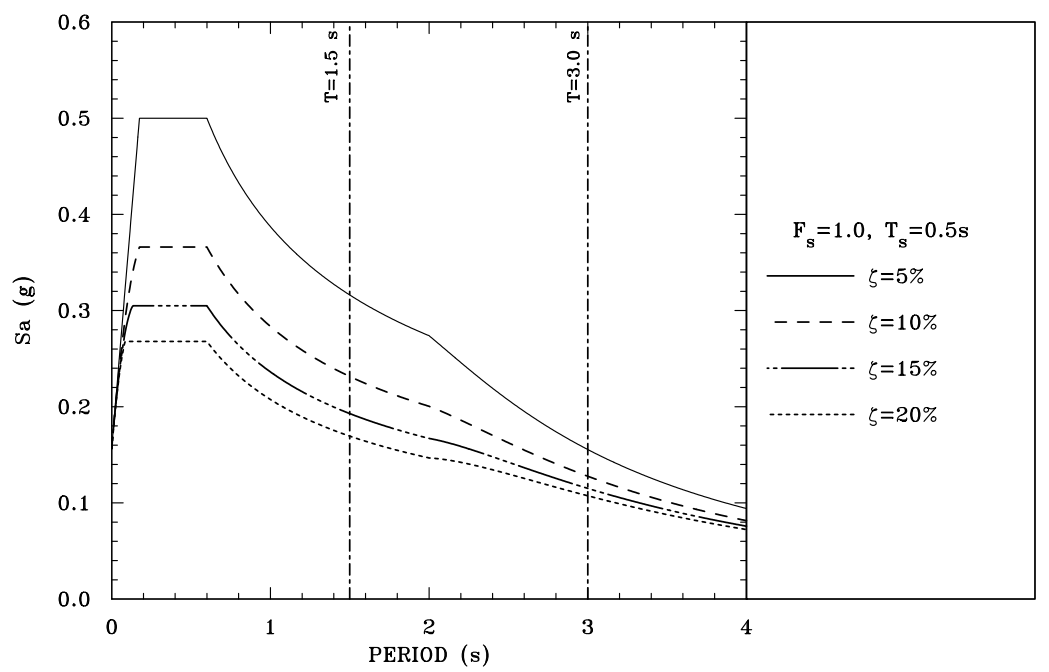

Fig. (2). Acceleration design spectra for MOC-2008 for a site where $a_{0}^{r}=0.157 \mathrm{~g}, T_{s}=0.5 \mathrm{~s}$ and $F_{s}=1$.

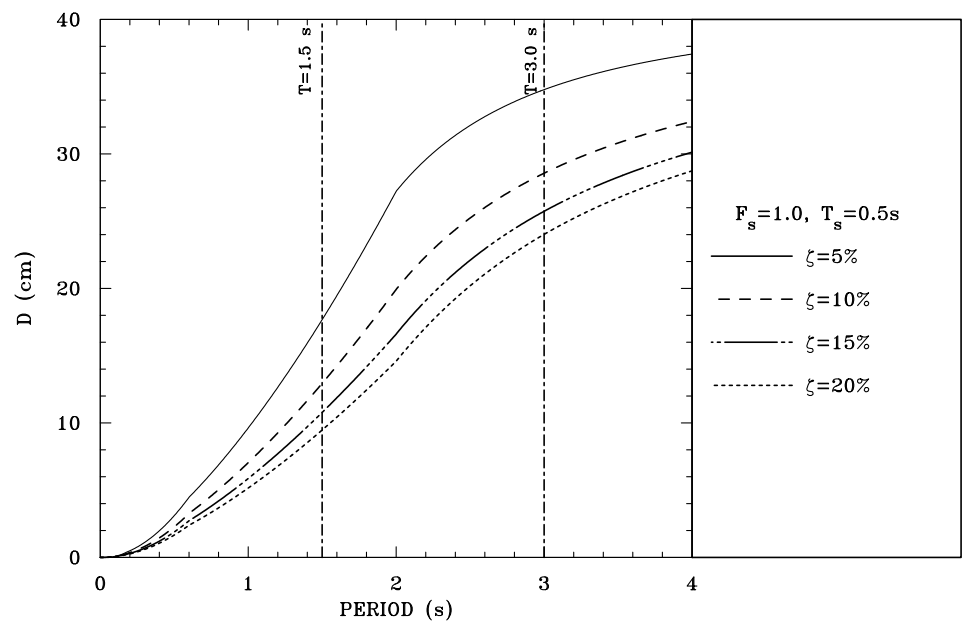

Fig. (3). Displacement design spectra for MOC-2008 for a site where $a_{0}^{r}=0.157 g, T_{s}=0.5 \mathrm{~s}$ and $F_{s}=1$. 


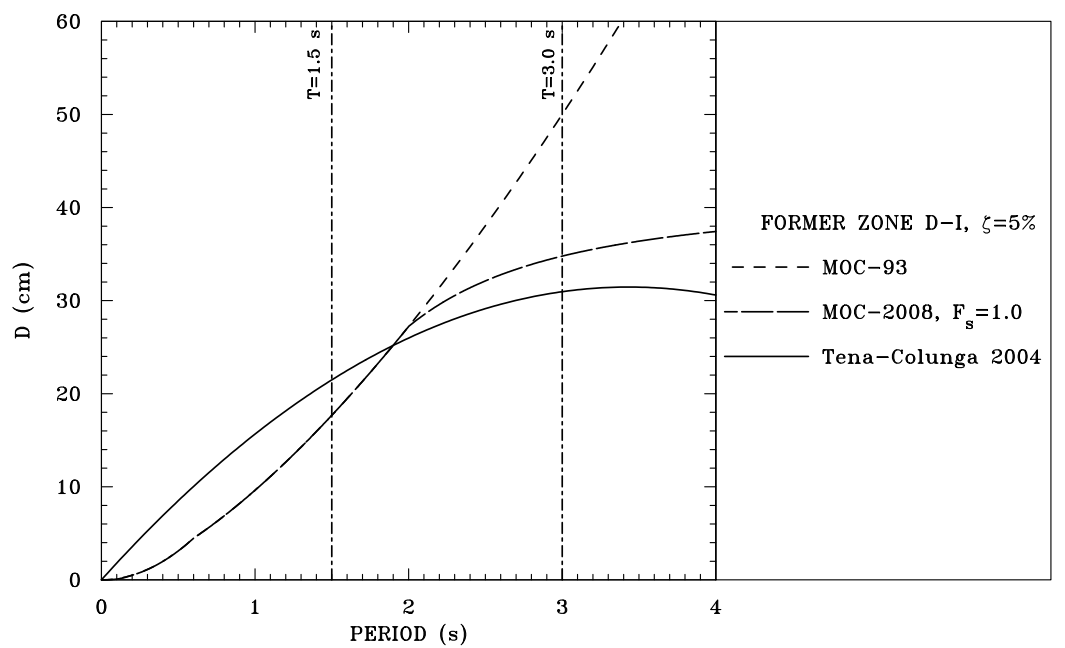

Fig. (4). Comparison of displacement design spectra for former zone D-I defined in MOC-93.

riod range of interest for base-isolated structures $\left(1.5 s \leq T_{a s} \leq 3 s\right)$. It is worth noting that the proposal in TenaColunga [4] was obtained using a basic probabilistic and statistical criteria based on displacement response spectra of approximately 250 ground motions recorded at stations located on rock sites from the Mexican Strong Motion Data Base [18] for subduction earthquakes of $\mathrm{M} \geq 6.4$. In contrast, in MOC-2008 [1] all known earthquake sources for the different regions of seismic risk of Mexico were taken into account, and their maximum credible earthquake (MCE) scenarios were defined using updated information. In addition, the seismic hazard in MOC-2008 was evaluated using both deterministic and probabilistic approaches $[1,2,19]$.

Another relevant aspect of MOC $[1,3]$ in the definition of the design spectra is that it is recognized that reductions due to supplemental damping (Eq. 5) are not constant and they depend on the structural period and the characteristics of the ground motion. Most international guidelines for the seismic design of base-isolated structures [9, 10, 20, 21] specify a constant reduction in sake of simplicity. Proposed reductions for supplemental damping according to $\mathrm{MOC}$ code $(1 / \beta)$ for former zone D-I of MOC-93 are compared in Fig. (5) with the proposal of $B_{\zeta}$ made by Tena-Colunga $[4,5]$ and the $B$ constant proposed by the international guidelines of reference. Proposed reductions in MOC $(1 / \beta)$ have a spectral shape as they were derived in order that the associated acceleration design spectra will keep their shape. $B_{\zeta}$ curves vary parabollically as they were derived from the quotient between corresponding mean displacement spectra. Given the differences in their derivation, in both the $(1 / \beta)$ and $B_{\zeta}$ curves, the effect of the natural period on the reduction factor due to supplemental damping is taken into account, contrary to other design regulations where such an effect is neglected. It is also worth noting that the constant reduction $(B)$ proposed by international guidelines seem to be somewhat conservative.

\section{REDUCTION OF ELASTIC RESPONSE PARAME- TERS FOR DESIGN}

According to what it was presented in previous sections, acceleration and displacement design spectra can be reduced for the supplemental damping provided by the isolation system at the design displacement $D_{T}$. Additional reductions are allowed in the acceleration design spectra to account for overstrength and redundancy only, as it is desired that the structure above the isolation system will remain essentially elastic when subjected to the MCE. These additional reductions should be assessed as described in following sections.

\section{Overstrength Reduction Factor $\boldsymbol{R}_{a s}$}

The proposal for the overstrength reduction factor for base-isolated structures, $R_{a s}$, is given by the following equations:

$\mathrm{R}_{\mathrm{as}}= \begin{cases}\mathrm{R}_{\mathrm{a} 0}+0.3\left(1-\sqrt{\mathrm{T}_{\mathrm{E}} / \mathrm{T}_{\mathrm{a}}}\right), & \text { if } \mathrm{T}_{\mathrm{E}} \leq \mathrm{T}_{\mathrm{a}} \\ \mathrm{R}_{\mathrm{a} 0} ; & \text { if } \mathrm{T}_{\mathrm{E}}>\mathrm{T}_{\mathrm{a}}\end{cases}$

where $T_{E}$ is the fixed-base fundamental period of the structure above the isolation system, $T_{a}$ is the lower boundary limiting period that defined the plateau for the acceleration design spectra (Fig. 1) and $R_{a 0}$ is an overstrength index value for the base-isolated structure that depends on the structural system. For example, $R_{a 0}=1.4$ for ordinary and intermediate moment-resisting frames, ordinary moment-resisting braced frames and confined masonry wall structures made with hollow units (ungrouted or partially grouted); $R_{a 0}=1.6$ for special moment-resisting frames, intermediate momentresisting braced frames, and confined masonry wall structures made with solid units; $R_{a 0}=1.7$ is for dual systems built with special moment-resisting frame connections.

The proposed $R_{a s}$ curves for MOC-2012 [3] are depicted in Fig. (6), where it can be observed that they vary with the structural system and the structural period. This is done because it is recognized that for squatty, short period structures $\left(T_{E} / T_{a}<1\right)$, the impact of gravitational load combinations in the design provides structures with additional lateral strength.

The proposal for the $R_{a s}$ factor for base-isolated structures is similar to the $R$ factor proposed for conventional buildings [1, 2], although their absolute values are smaller. This is justified as follows. The $R$ factors for the design of conventional structures accounts for the maximum over- 


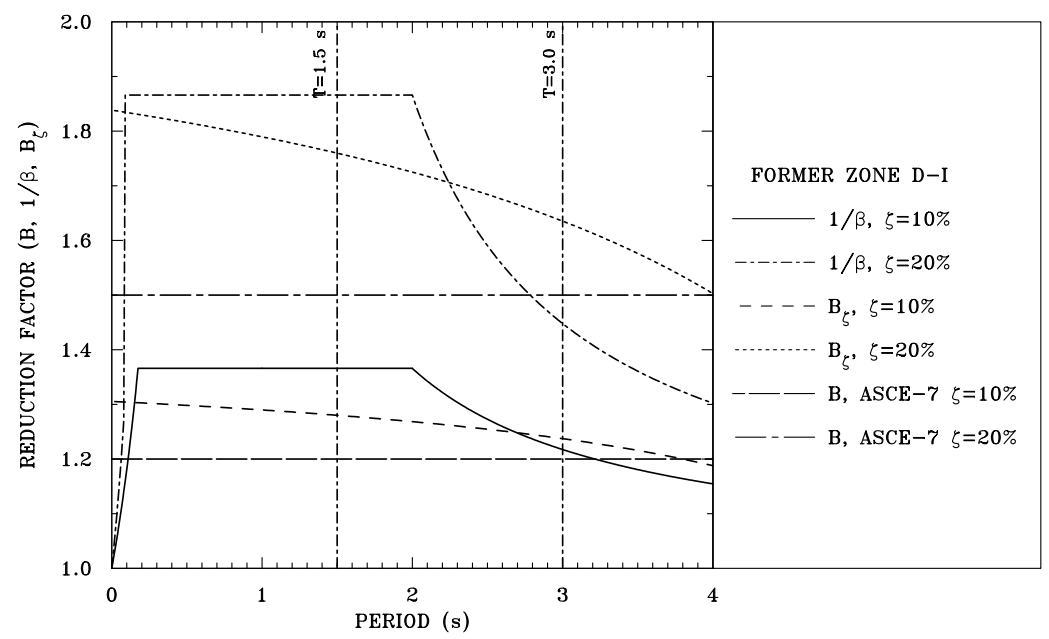

Fig. (5). Comparison of different reduction factors to account for supplemental damping.

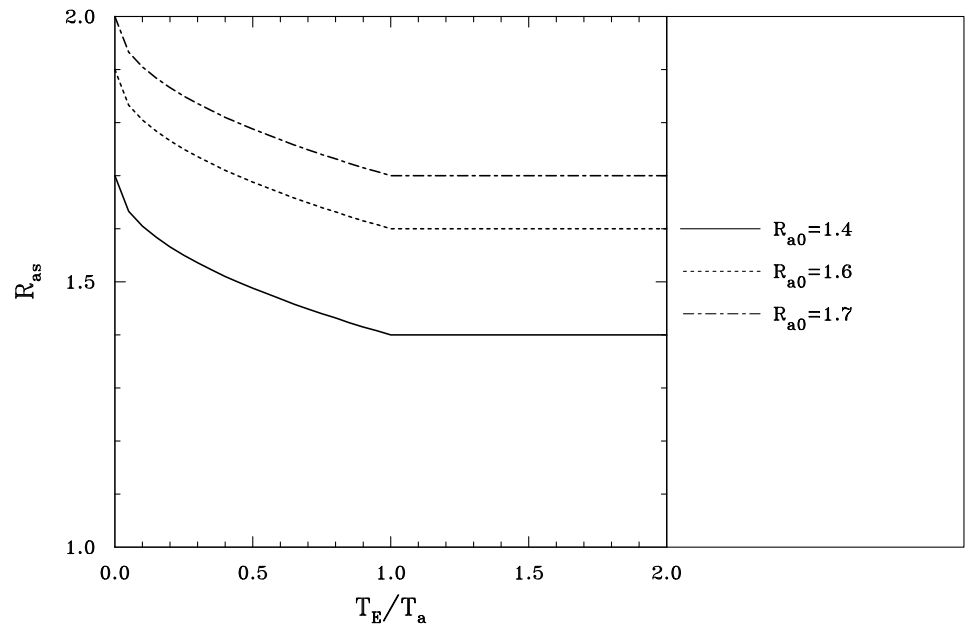

Fig. (6). Overstrength reduction factors for base isolated structures $R_{a s}$ for MOC-2012.

strength that the structural system can develop under lateral loading if its maximum deformation capacity is achieved. In contrast, $R_{a s}$ factors for the design of base-isolated structures accounts for sources of overstrength that trigger within the elastic range of response (up to the elastic limit), as they depend primarily on design decisions rather than in ultimate deformation capacity under lateral loading. Among such sources of overstrength are the selection of typical cross sections, minimum strength requirements for structural elements, impact of gravitational loads on the design, etc.

The proposed values for $R_{a 0}$ are based on the analysis of results presented in studies conducted in Mexico where the minimum nominal strength was assessed for some structural systems such as ordinary and special moment-resisting RC [22] and steel frames [23] and special moment-resisting concentric braced frames [24, 25]. Of course, the current proposal of MOC has room for improvement as more reliable data regarding the assessment of overstrength for different structural systems will be available in the future.

\section{Redundancy Factor $\rho_{\text {as }}$}

The introduction of a specific redundancy factor for base isolated structures $\rho_{a s}$ is a new concept for seismic design codes worldwide, not only for MOC-2012 [3]. The purpose of this "new" factor is recognizing directly that base-isolated structures have a better performance under lateral earthquake loading as they become more redundant. This fact is wellknown by the structural engineering community worldwide $[17,26]$. Therefore, this new $\rho_{a s}$ factor allows higher reductions for the design of highly redundant base-isolated structures and penalizes weakly-redundant base-isolated structures with smaller reductions for design.

The proposed values for $\rho_{a s}$ in MOC-2012 [3] are the following:

$\rho_{\text {as }}=0.8$ for buildings with isolation systems that have at least two earthquake-resistant parallel frames or lines of defense in the direction of analysis, if such frames are onebay frames (or equivalent structural systems). The same concept shall be simultaneously satisfied by the baseisolation system.

$\rho_{a s}=1$ for buildings with isolation systems that have at least two earthquake-resistant parallel frames or lines of defense in the direction of analysis, if such frames have at least two bays (or equivalent structural systems). The same 
concept shall be simultaneously satisfied by the baseisolation system.

$\rho_{a s}=1.25$ for buildings with isolation systems that have at least three earthquake-resistant parallel frames or lines of defense in the direction of analysis, if such frames have at least three bays (or equivalent structural systems). The same concept shall be simultaneously satisfied by the baseisolation system.

The proposed values for $\rho_{a s}$ for base isolated structures coincide with the values proposed for $\rho$ for conventional structures $[1,2]$. This was done for simplicity in lieu of specific studies that may justify differences between $\rho$ and $\rho_{a s}$.

The assessment of the $\rho_{a s}$ factor for a given base-isolated structure is straight-forward and it will be illustrated with the aid of the building plans depicted in Fig. (7). Often, the number of isolators is equal or less the number of column lines for the building, so the definition of the $\rho_{a s}$ factor is generally ruled by the isolation system. For the building plan depicted in Fig. (7a), $\rho_{a s}=0.8$ should be taken in the $\mathrm{Y}$ direction as the isolation system is forming an equivalent "three parallel one-bay frames system", whereas in the X direction, $\rho_{a s}=1$ because the isolation system is forming an equivalent "two parallel two-bay frames system". In contrast, for the building plan depicted in Fig. (7b), $\rho_{a s}=1.25$ should be taken in the $\mathrm{Y}$ direction as the isolation system is forming an equivalent "five parallel three-bay frames system", whereas in the $\mathrm{X}$ direction, $\rho_{a s}=1.25$ also because the isolation system is forming an equivalent "four parallel four-bay frames system".

This simple example illustrates the philosophy behind the new $\rho_{a s}$ factor. A-priori, most engineers would agree that the base-isolated building, the plan of which is depicted in Fig. (7b), is more redundant than the base-isolated building which plan is depicted in Fig. (7a). It is hoped that this approach would help structural engineers to promote the use of more redundant base-isolated buildings in zones of high earthquake hazard and to limit or avoid the use of weaklyredundant isolation systems (i.e., Fig. 7a).

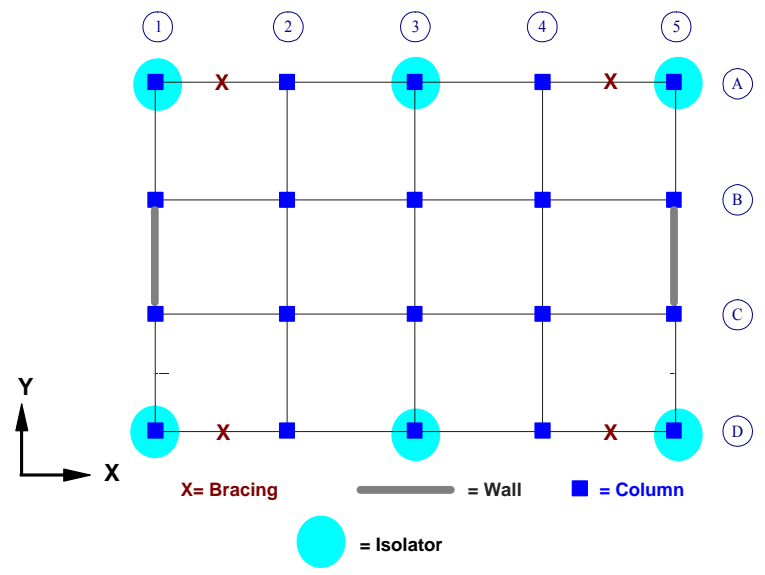

a) Less redundant isolation system
Seismic Reduction Factor $Q_{a s}^{\prime}$

The acceleration design spectra for base-isolated structures could be further reduced for overstrength and redundancy (Fig. 8) in terms of a seismic reduction factor for baseisolated structures, $Q_{a s}^{\prime}$, given by the following expressions:

$$
\mathrm{Q}^{\prime}{ }_{\mathrm{as}}= \begin{cases}\mathrm{R}_{\mathrm{as}} \rho_{a s} \geq 1 ; & \text { if } \frac{\mathrm{T}_{\mathrm{as}}}{\mathrm{T}_{\mathrm{E}}} \geq 5 \\ \mathrm{R}_{\mathrm{as}} \rho_{a s}\left(0.5+0.1 \frac{T_{a s}}{T_{E}}\right) \geq 1 ; & \text { if } 2 \leq \frac{\mathrm{T}_{\mathrm{as}}}{\mathrm{T}_{\mathrm{E}}}<5\end{cases}
$$

The proposal for $Q_{a s}^{\prime}$ is similar to the one presented in previous recommendations for base isolated structures in Mexico $[4,5]$. The normalized $Q_{a s}^{\prime} / R_{a s} \rho_{a s}$ vs $T_{a s} / T_{E}$ curve is depicted in Fig. (9).

As it can be observed from Eq. 8 and Fig. (9), higher reductions are allowed for structures where the effective base-isolated fundamental period $T_{a s}$ is considerably higher than its corresponding fixed-base period $T_{E}$. It is well known in the literature that when that occurs, the seismic demands in the structure above the isolation system are considerably reduced, but the reductions are not as high when $T_{E}$ approaches to $T_{a s}$. The limits are based on the observation of amplification curves presented in many studies available in the literature [27], as well as in studies conducted by the author $[28,29,30]$. The lower limit for $T_{a s} / T_{E}=2$ is consistent with the minimum value allowed in MOC-2012 guidelines to use the static design force procedure, which is originally based on a recommendation available in Skinner et al. [27], that has been further evaluated, including torsional effects, as reported elsewhere [30,31].

From the values specified for $R_{a s}$ and $\rho_{a s}$ in MOC-2012 [3], it is obtained that the maximum value for the seismic reduction factor for base isolated structure is $Q_{a s}^{\prime}=2 x 1.25=2.5$ for highly redundant structures when $T_{a s} / T_{E}>5$ The minimum value is $Q_{a s}^{\prime}=1$ for weaklyredundant base-isolated structures, with low overstrength and when the $T_{a s} / T_{E}$ ratio is low. It is worth noting that in baseisolated guidelines of the United States $[9,10,20,21]$ reduc-

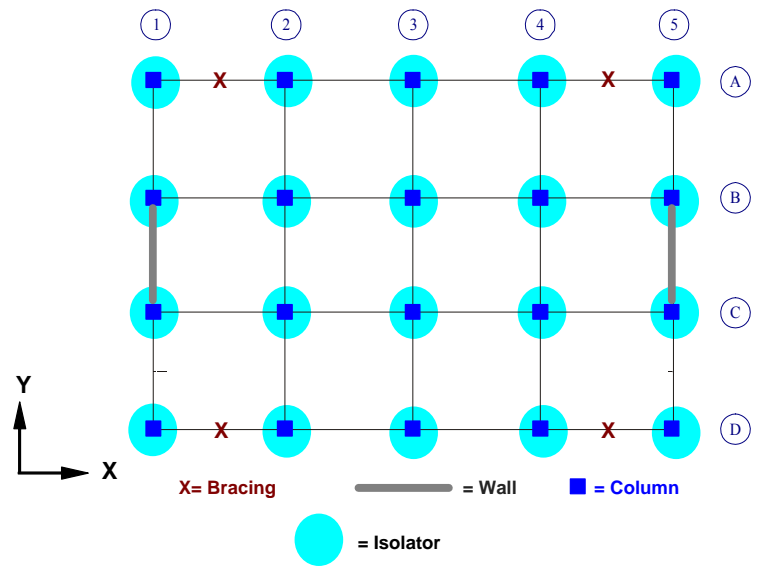

b) More redundant isolation system

Fig. (7). Sample buildings to illustrate the assessment of the $\rho_{a s}$ factor. 


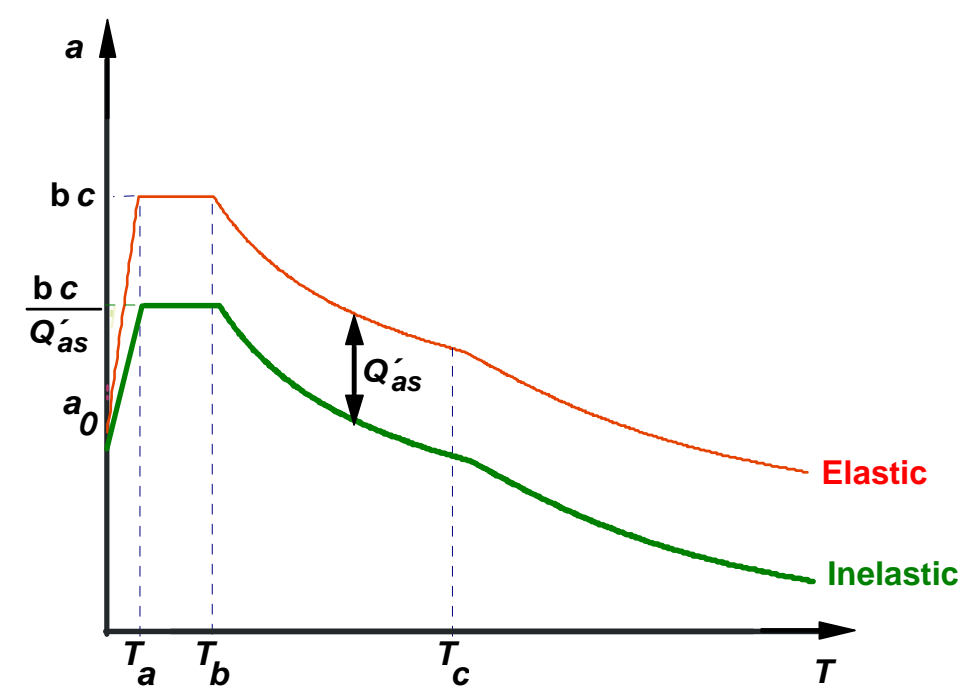

Fig. (8). Schematic representation of inelastic acceleration design spectra for base-isolated structures for MOC-2012.

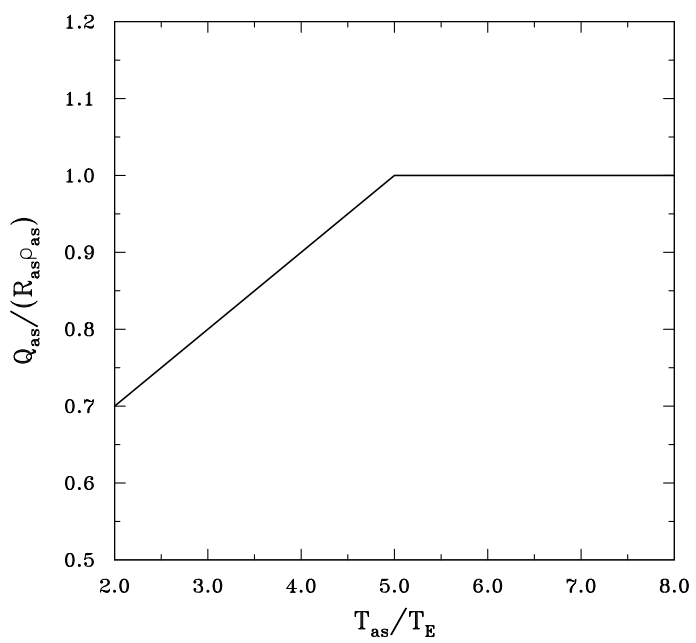

Fig. (9). Normalized $Q_{a s}^{\prime} / R_{a s} \rho_{a s}$ vs $T_{a s} / T_{E}$ curve for base-isolated structures for MOC-2012.

tions due to redundancy and overstrength for base-isolated structures ranges from 1.4 to 2.0 depending on the structural system, as previously pointed out by Naeim and Kelly [32].

Finally, following the design philosophy of Mexican seismic codes, if the base-isolated structure does not satisfy the conditions of structural regularity, $Q_{a s}^{\prime}$ must be reduced, as it will be discussed in more detail in following sections.

\section{CONDITIONS OF STRUCTURAL REGULARITY}

For the design of base-isolated structures, twelve conditions of regularity are defined and building structures must satisfy them in order to use directly the seismic force reduction factor $Q_{a s}^{\prime}$. These conditions are mostly the eleven condition of regularity for conventional building specified since MOC-93 [i.e., 6] that mostly remain the same for the design of conventional buildings in MOC-2008 [1, 2], but the statement devoted to prevent a soft story condition (condition \# 10) was redefined and now is more conservative than in previous versions [2].
For the design of base-isolated structures, the limits of original structural regularity conditions 2 (slenderness) and 3 (plan aspect ratio) are also lowered, based upon what it is recommended in Naeim and Kelly [32] and Tena-Colunga [33]. In addition, a new condition of structural regularity 12 is set to limit the static eccentricity in the isolation system which it is based on some specific studies [34-37]. Therefore, the conditions of regularity that have been redefined or inserted for the design of base-isolated structures are:

2. The ratio of the height of the building to the smallest plan dimension shall not exceed $2.0\left(H / L_{2} \leq 2.0\right)$.

3. The ratio of the largest to the smallest plan dimensions shall not exceed $2.0\left(L_{1} / L_{2} \leq 2.0\right)$.

10. The lateral shear stiffness or strength of any story shall not exceed more than 50 percent the shear stiffness or strength of the adjacent story below the one in consideration. The top story is exempt from this requirement.

11. The torsional plan eccentricities $\left(e_{s}\right)$, computed for any story from static seismic analysis, shall not exceed 10 percent of the plan dimension in the given direction of analysis. 
12. The torsional eccentricity for the isolation system $\left(e_{s a}\right)$, shall not exceed 5 percent of the plan dimension in the given direction of analysis.

The remaining conditions of structural regularity can be read in English as outlined elsewhere [2, 6].

Similar to what it was done for the design of conventional buildings $[1,2]$, if a base-isolated building satisfies all the twelve conditions of structural irregularity, it is defined as a regular structure, so $Q_{a s}^{\prime}$ remains unchanged. However, if at least one condition of structural regularity is not satisfied, the base-isolated building is defined as irregular structure, and then $Q_{a s}^{\prime}$ is reduced for design purposes as follows:

$Q_{\text {as-irregular }}^{\prime}=\alpha Q_{\text {as-regular }}^{\prime}$

where $\alpha$ is a corrective reduction factor that depends on the degree of irregularity according to MOC [1-3]. If a building does not satisfy one regularity condition (from those numbered 1 to 9), then $\alpha=0.9$. If a building does not satisfy regularity condition 10 (soft story) or 11 (torsion in the superstructure), or 12 (torsion in the isolation system), or two or more of the remaining regularity conditions (1 to 9) are not satisfied, then $\alpha=0.8$. If a building has a strong irregularity, then $\alpha=0.7$.

Strong irregularity conditions are defined as follows: (1) If conditions 10 (soft story) and 11 (torsion in the superstructure) are not satisfied simultaneously, (2) a strong torsional irregularity in the superstructure is met, evaluated in terms of a static eccentricity greater than 20 percent of the plan dimension in the given direction of analysis $\left(e_{s}>0.20 L\right)$, (3) a strong torsional irregularity in the isolation system is met, evaluated in terms of a static eccentricity greater than 15 percent of the plan dimension in the given direction of analysis $\left(e_{s a}>0.15 L\right),(4)$ a strong soft story condition is found, where the lateral shear stiffness or strength of any story exceeds more than 100 percent the shear stiffness or strength of the adjacent story below the one in consideration.

It is recognized in the proposed guidelines that the main source of torsional motions in isolated structures (particularly with elastomeric bearings) is the isolation system eccentricity, especially when the eccentricity is large. This is why the design of base-isolated structures is severely punished when $e_{s a}$ is greater than $5 \%$ or $15 \%$. The limiting values for static eccentricities in the superstructure $\left(e_{s}\right)$ and in the isolation system $\left(e_{s a}\right)$ to define when a base-isolated structure should be considered irregular or strongly irregular were proposed after reviewing primarily the results presented in the extensive parametric studies [30, 31, 37, 38]. In addition, other results presented in the literature were carefully reviewed as well [17, 26, 34-36, 39-44].

Finally, it is worth noting that there are some studies where base-isolated structures have been designed as irregular buildings using the corrective reduction factor $\alpha$ adapting the former MOC- 93 code and using $\alpha=0.8$ [i.e., 28, 29, 45, 46]. From the results presented in these studies, it was found that using $\alpha=0.8$ seem to be an effective strategy to lead to safe designs of base-isolated buildings that do not satisfy two or more conditions of structural regularity.

\section{METHODS OF ANALYSIS}

Three methods of seismic analysis are allowed for baseisolated structures in MOC-2012 [3]: a) the simplified method, b) the static method and, c) dynamic methods.

\section{Simplified Method}

The simplified method is allowed for low-rise (up to four stories or less than $13 \mathrm{~m}$ in height), shear-wall structures where seismic forces are distributed among structural elements according to their shear stiffnesses.

This simplified method is a hybrid method where the design of the isolation system is a simpler but more restrictive version for the static method for base-isolated structures (similar to US guidelines) and the design of the superstructure essentially is the improved simplified method for the design of conventional structures but the effective shear area factors $\left(F_{A E}\right)$ that are defined for the walls are those for elastic response [1-3, 47]. The effects of the vertical component of the ground motions are neglected in the design process when using the simplified method.

In order to use the simplified method of analysis, the base-isolated structure should satisfy the 12 conditions of structural regularity, but stricter requirements are set for torsional response, as $e_{s a}$ and $e_{s}$ shall not exceed 2 and 5 percent of the plan dimension in the given direction of analysis respectively. The limiting value for $e_{s}$ is based on the results of a detailed parametric study [48]. Among other stricter requirements with respect to the static method, are the following: (1) The base-isolated structure should be located more than $50 \mathrm{~km}$ away from any active fault, and, (2) The effective natural period of the base-isolated structure at the design displacement, $T_{a s}$, should be greater than five times the elastic, fixed-base period of the structure above the isolation system, $T_{E}$, this is, $T_{a s} \geq 5 T_{E}$. This method is presented in greater detail elsewhere $[49,50]$.

\section{Static Method}

The static method in MOC-2012 [3] is very similar to the one presented in the previous guidelines of the seismic design of base-isolated structures in Mexico [4, 5]. Therefore, the static method is based on adaptations for the procedures outlined in design guidelines of the United States [9, 10, 20, $21]$ to the seismic design philosophy of current MOC code, but having some original proposals from research studies conducted in Mexico and worldwide.

The requirements to use the static method that are somewhat different in reading from those established in US guidelines are:

- The structure above the isolation interface is not more than $20 \mathrm{~m}$ in height.

- The base-isolated structure is located on firm soils or rock [the site factor ranges from 1.0 to 1.25 $\left(1.0 \leq F_{s} \leq 1.25\right)$ or the shear wave velocity is $v_{s} \geq 250 \mathrm{~m} / \mathrm{s}$. 
- The effective period of the base-isolated structure at the design displacement, $T_{a s}$, is greater or equal to $1.5 \mathrm{sec}-$ onds but less or equal to 3.0 seconds, this is, $1.5 s \leq T_{a s} \leq 3 s$.

- The effective period of the base-isolated structure at the design displacement, $T_{a s}$, is greater than two times the elastic, fixed-base period of the structure above the isolation system, $T_{E}$, this is, $T_{a s} \geq 2 T_{E}$.

The following requirement set in MOC-2012 to use the static method is not currently considered in US guidelines:

- The base-isolated structure complies with all twelve regularity conditions outlined in the guidelines.

As 3D-analyses are mandatory for base-isolated structures, the static method requires the determination of the natural period for the base-isolated structure in the vertical direction, $T_{\text {asv }}$, as:

$T_{a s v}=2 \pi \sqrt{\frac{W}{g k_{a s v}}}$

where $W$ is the weight of the structure above the isolation system and $k_{a s v}$ is the effective vertical stiffness of the isolation system. There are procedures to determine $k_{\text {asv }}$ already available in the literature $[27,32,51]$.

The design displacement of the center of stiffness of the isolation system in the direction of analysis for the MCE, $D_{D}$, is computed as:

$D_{D}=F_{c} S_{d}\left(T_{a s}\right)$

where $F_{c}=1.1$ is the load factor for combinations of lateral and gravitational loads.

This design displacement has to be amplified to account for orthogonal effects in the horizontal plane $\left(D_{2 D}\right)$ as follows, based on an extensive parametric study summarized elsewhere [52]:

$D_{2 D}=D_{D}\left(1.3-0.02 T_{a s}\right) ; \quad T_{a s} \geq 1.5 s$

The amplification of the total design displacement $\left(D_{T}\right)$ to account for torsional effects is an improved version of the equation proposed by US guidelines to include 2D directional effects and account for the rotational to translational frequency ratio of the isolation system $\left(\Omega_{0 \text { as }}\right)$ and is given by the following two equations:

$D_{T}=D_{2 D}\left[1+y_{i}\left(\frac{12 e}{\Omega_{0 a s}\left(d_{1}^{2}+d_{2}^{2}\right)}\right)\right] \geq 1.1 D_{2 D}$

$\Omega_{0 a s}=\frac{\omega_{\theta a s}}{\omega_{a s}}=\frac{T_{a s}}{T_{\theta a s}}$

where $e$ is the actual eccentricity, measured in plan between the center of mass of the structure above the isolation interface and the center of stiffness of the isolation system, plus accidental eccentricity, taken a five percent of the longest plan dimension of the structure perpendicular to the direction of force under consideration. The remaining terms are: $d_{l}$ and $d_{2}$ are respectively the shortest and the longest plan di- mensions of the structure and $y_{i}$ is the distance between the center of stiffness of the isolation system and the element of interest measured perpendicular to the direction of the seismic loading under consideration.

It can be observed that if $\Omega_{0 a s}=1$ and $D_{2 D}=D_{D}$, then Eq. 13 coincides with what it is proposed in US guidelines [9, $10,20,21]$. The introduction of $\Omega_{0 a s}$ is supported by the study presented by Seguín [17], where it is demonstrated that if the rotational to translational frequency ratio of the isolation system is not introduced ( $\Omega_{0 a s}=1$, i.e., US guidelines), that strategy lead to large, very conservative amplification factors when they are compared with those obtained from dynamic analyses, particularly for torsionally-stiff systems $\left(\Omega_{0 \text { as }}>1\right)$.

The minimum design shear force for the isolation system, the foundation and structural elements below the isolation system, $V_{a s}$, is computed similarly to what is done in US guidelines:

$V_{a s}=k_{D \max } D_{2 D}$

where $k_{D \max }$ is the maximum effective stiffness of the isolation system at the design displacement in the horizontal direction under consideration. The value for $V_{a s}$ should not be taken less than the maximum force in the isolation system at the design displacement $D_{T}$.

The equation to define $V_{E}$, the minimum design shear force for the structure above the isolation system is:

$V_{E}=\frac{V_{a s}}{Q_{a s}^{\prime}}$

It is worth noting that the limits in $V_{E}$ mostly coincide with current proposal of ASCE-7 [9] as per section 17.5.4.3, but item 3 is not included in MOC-2012 [3].

The vertical distribution of forces in the superstructure are given by the following expressions:

$F_{i}=\left\{\begin{array}{lll}V_{E} \frac{W_{i}}{\sum W_{i}} \text { if } & \frac{T_{a s}}{T_{E}} \geq 5 \\ V_{E} \frac{W_{i} h_{i}}{\sum W_{i} h_{i}} \text { if } & \frac{T_{a s}}{T_{E}}<5\end{array}\right.$

where $F_{\mathrm{i}}, W_{i}$ and $h_{i}$ are respectively the lateral force, the weight and the height above the isolation system of level $i$. and the remaining terms have been already defined. As observed, in MOC-2012 a uniform lateral load distribution is allowed for base-isolated structures that are well uncoupled $\left(T_{a s} / T_{E} \geq 5\right)$, that it is a more rational approach. An inverted triangular lateral load distribution is specified otherwise. The proposed limiting value $T_{a s} / T_{E}=5$ between the uniform and the inverted triangular lateral load distribution is based on the analysis of results presented in some studies [28-30]. However, specifically-oriented parametric studies are required to assess the most appropriate limiting value between both force distributions or to involve the $T_{a s} / T_{E}$ ratio in the expressions for $F_{i}$, in order to have a smooth transition be- 
tween the uniform and the inverted triangular lateral load distribution.

To account for the vertical component of the ground motion, the equivalent normal forces (tension and compression) induced to the isolation system $\left(N_{\text {asv }}\right)$ and to the base of the structure $\left(N_{E}\right)$ can be approximately estimated as:

$N_{a s v}=N_{E}=1.4\left(\frac{0.05}{T_{a s v}}\right)^{2 / 3} S_{a}\left(T_{a s h}\right) W$

where $T_{a s v}$ is the natural period for the base-isolated structure in the vertical direction, $T_{a s h}$ is the smaller of the natural periods for the structure in the horizontal direction, $W$ is the total weight for the structure above the isolation system, and $S_{a}\left(T_{a s h}\right)$ is the acceleration spectral ordinate at period $T_{a s h}$ already reduced for supplemental damping $\beta$. It is worth noting that Eq. 18 is based on the vertical design spectrum already proposed in MOC-2008 for the design of conventional buildings $[1,2]$.

Accordingly, the distribution of vertical forces in the superstructure due to the action of the vertical ground component is computed assuming a uniform distribution as:

$N_{i}=N_{E} \frac{W_{i}}{\sum W_{i}}$

where $N_{i}$ is the total vertical force acting at level $i$ due to vertical component of the ground motion and the remaining terms have already been defined.

The effects of the vertical component of the ground motion can be neglected for structures located more than $50 \mathrm{~km}$ away from any active fault.

Additional torsional effects due to eccentricities in the superstructure should be included in the analyses of the superstructure as outlined for conventional buildings.

P- $\Delta$ effects should be included in the analysis of baseisolated structures when the superstructure is very flexible, defined when the following two conditions are satisfied simultaneously: $T_{a s} / T_{E} \leq 3$ and $T_{E} \geq 0.15 \mathrm{~N}$, where $N$ is the number of stories for the structure above the isolation system.

Besides these additional requirements for torsional and P$\Delta$ effects, special provisions are also specified to account for overturning moments and asymmetric strength capacity in the two principal axes of the building that are also mostly addressed in the design of conventional buildings $[1,2]$.

\section{Dynamic Method}

The dynamic method established in MOC-2012 [3] is also based on adaptations for the procedures outlined in US guidelines to current seismic design philosophy of MOC. Therefore, response spectrum and time-history analyses are specified. However, there are some adjustments (differences) worth noting with respect to the general guidelines established in US codes $[9,10,20,21]$.
For example, an acceleration design spectrum for the vertical component of the ground motion $S_{a v}\left(T_{v}\right)$ is specified for an equivalent $5 \%$ viscous damping $(\beta=1)$ as follows:

$S_{a v}\left(T_{v}\right)= \begin{cases}1.4 S_{a}\left(T_{h}\right) & \text { if } \quad T_{v}<0.05 s \\ 1.4 S_{a}\left(T_{h}\right)\left(\frac{0.05}{T_{v}}\right)^{2 / 3} & \text { if } \quad T_{v} \geq 0.05 s\end{cases}$

where $S_{a v}\left(T_{h}\right)$ is the acceleration design spectrum of the largest horizontal ground component and the remaining terms have already being defined. This vertical spectrum is also specified for the design of conventional buildings $[1,2]$ and it is based in the study presented by Perea and Esteva [53]. The effects of the vertical component of the ground motions can be neglected for structures located more than 50 $\mathrm{km}$ away from any active fault.

Directional orthogonal effects in the horizontal plane are amplified with a similar expression to the one established for the static method. Therefore, for each direction of analysis, the effects of the ground components will be combined taking $100 \%$ of the effects of the ground motion component acting along that direction $\left(E_{x}\right)$ and $100 \%\left(0.3-0.02 T_{a s}\right)$ of the effects of the component perpendicular to the former one $\left(E_{y}\right)$ with the signs that, for each concept, lead to the most unfavorable condition.

In the response spectrum analysis, accidental torsional effects are accounted in the design by translating $\pm 0.05 b_{n}$ the centers of mass at each level for each horizontal direction of analysis. This recommendation would require the use of four additional models to assess the impact of the modal coupling due to accidental torsion. As an option, one can use a single model if the line of action of the lateral forces obtained from the response spectrum analysis are translated $\pm 0.05 b_{n}$ at each level, this is, static torques are applied as an approximation of the modal coupling due to accidental torsion. In addition, SRSS or CQC combination procedures are specified; however, it is clearly stated that SRSS method can only be used if the natural periods for the building in each given direction differ in $10 \%$ or more.

For time-history analysis, it is clearly specified that the acceleration ground motions to be included in the analyses must be fully compatible with the seismic hazard for the site of interest, as outlined in a specialized section of the manual. Three orthogonal ground motion components (two horizontal and one vertical) should be included in the analyses of structures located at a distance equal or less than $50 \mathrm{~km}$ away from any active fault or in structures where the action of the vertical component might be relevant. Otherwise, at least two orthogonal horizontal ground motion components must be included in the analyses. At least four representative trios (or duos) of representative ground motions should be included in the analyses. The nonlinear response of the isolation system, the effective damping for the isolation system and/or the structure above the isolation system and their associated uncertainties should be also taken into account. 
Each trio or pair of time histories must be applied simultaneously to the model considering the most disadvantageous location of mass eccentricity. The maximum displacement of the isolation system must be calculated from the vectorial sum of the orthogonal components at each time step. The parameter of interest must be calculated for each timehistory analysis. If seven or more trios (or duos) of timehistory analyses are performed, the average value of the response parameter of interest should be used for design. If fewer than seven trios (or duos) of time-history analyses are performed, the most unfavorable response of the parameter of interest must be used for design.

An alternate method is also allowed in MOC-2012 [3], named simplified nonlinear dynamic analysis. Under this method, a base-isolated structure can be design based upon inelastic spectra obtained from SDOF systems [i.e., 54], assessing the maximum design displacement and shear force for the isolation system as well as the maximum shear force and acceleration for the structure above the isolation system. To use this method, the following requirements should be met: (a) A representative hysteretic model should be used for the isolation system, (b) At least 15 pairs or trios of acceleration records should be used to define the average value of the response parameter of interest, (c) The uncertainties in the estimates of the effective period for the base-isolated structure, the yield force, post yielding stiffness, coefficient of friction, equivalent viscous damping or any other relevant parameter that defines the nonlinear response or damping characteristics of the isolation system should be taken into account in the analyses.

The total design displacement is computed as in US guidelines $[9,10]$, including reductions that take into account the flexibility of the structure above the isolation system.

The minimum design shear force for the structure above the isolation system, $V_{E}$, is also defined, reviewed and scaled (if necessary) according to US guidelines. However, the minimum percentages with respect to the shear force obtained from an static analyses slightly differ in some cases, because these reductions should be compatible with those specified in MOC-20008 for the design of conventional buildings [1,2], particularly because of the definitions of irregular and strongly irregular structures.

As noted in the static method, special provisions are specified to account for P- $\Delta$ effects, overturning moments and asymmetric strength capacity in the two principal axes of the building that are also mostly addressed in the design of conventional buildings $[1,2]$.

\section{REVIEW OF LIMIT STATES}

Four limit states have to be reviewed for seismic loading for base-isolated structures: (a) Story drift limits for the service earthquake, (b) Story drift limits for near elastic response of the structure above the isolation system for the maximum credible earthquake (MCE), (c) Glass gaps under the MCE and, (d) Buildings separations under the MCE.

The recommendations for glass gaps remain unchanged for this manual $[1,6]$. For buildings separations, it is established that base-isolated structures should be separated from an adjacent structure a distance equal to $1.5 D_{T}$ plus the computed horizontal displacement at the level of interest.

The review of drift limits for the service earthquake in MOC-2012 [3] is a new proposal for the design of baseisolated structures in México. For the service earthquake, the proposed story drift limits are $\Delta_{\text {ser }} \leq 0.001$ if non-structural elements are not properly separated from the structural system and $\Delta_{\text {ser }} \leq 0.002$ if non-structural elements are properly separated from the structural system.

Story drift limits defined for near elastic response for the superstructure under the MCE are function of the structural system. The proposed drift limits are given in Table $\mathbf{1}$. The proposed drift limits are based on studies conducted in Mexico where the drift value that defines the initial yielding for each story of building models using nonlinear analyses (dynamic and/or pushover) have been reported. These studies have been conducted for $\mathrm{RC}$ and steel moment frames [i.e., $22,23]$ and RC and steel braced frames [i.e., 24, 25]. For masonry structures, these values have been defined from experimental testing conducted in Mexico [i.e., 55-61].

The proposed story drift limits were compared with the maximum dynamic drifts reported for base-isolated structures in several analytical studies, particularly studies where building models were subjected to acceleration records compatible with the design spectra of previous MOC-93 code [i.e., 45, 46, 54]. It was confirmed that the proposed story drift limits are not restrictive for base-isolated structures with satisfactory performance.

\section{OTHER DESIGN REQUIREMENTS}

The following sections are almost entirely based on US guidelines $[9,10,20,21]$ : (a) Analysis and design of components at, above, below or crossing the isolation interface, (b) Detailed system requirements, (c) Design and construction review and, (d) Required testing for the isolation system. However, there are some minor modifications and additional precisions required to make these guidelines coherent as well as compatible with all regulations adopted by MOC-2008 [13].

For example, in US guidelines the required prototype tests are defined in terms of two design displacements $\left(D_{D}\right.$ and $D_{M}$ ). In MOC-2012 guidelines [3], the required testing is redefined in terms of one displacement only, the total design displacement $\left(D_{T}\right)$.

Also, in MOC-2012 there is a more rigorous policy regarding inspection and replacement compared to US codes. In MOC-2012 a base-isolated structure must have a structural safety certificate at all times that has to be extended by an official authority (i.e, Building Official Authority) based on the required inspections by the code (similar to US codes). This certificate must be renewed every four years for standard occupancy structures (group B) and every two years for very important and essential facilities (groups $\mathrm{A}$ and $\mathrm{A}^{+}$), or after an earthquake $M \geq 6.5$ on the Richter scale strikes the area where the base-isolated structure is located.

Selective testing of at least two representative isolators extracted from the base-isolated structure is mandatory every 
Table 1. Story Drift Limits of MOC-2012 for Near Elastic Response of the Superstructure of Base-isolated Structures Under the MCE

\begin{tabular}{|c|c|}
\hline Structural SYSTEM & Drift Limit \\
\hline Special moment-resisting (ductile) reinforced concrete $(\mathrm{RC})$ frames $(\mathrm{Q}=3$ or 4$)$ & 0.004 \\
\hline Ordinary or intermediate moment-resisting $\mathrm{RC}$ frames $(\mathrm{Q}=1$ or 2$)$ & 0.003 \\
\hline Ordinary or intermediate moment-resisting steel frames $(\mathrm{Q}=1$ or 2$)$ & 0.004 \\
\hline Eccentric braced steel frames & 0.005 \\
\hline Concentric braced steel frames & 0.004 \\
\hline Concentric braced RC frames & 0.0025 \\
\hline Dual system: $\mathrm{RC}$ walls with ductile $\mathrm{RC}$ frames $(\mathrm{Q}=3)$ & 0.003 \\
\hline Confined masonry wall system made with solid units and with horizontal steel reinforcement (joint reinforcement or wire mesh) & 0.0015 \\
\hline $\begin{array}{l}\text { Confined masonry wall systems: (a) walls made with solid units and, (b) walls made with hollow units and with horizontal steel rein- } \\
\text { forcement (joint reinforcement or wire mesh) }\end{array}$ & 0.0015 \\
\hline Combined and confined masonry wall systems & 0.0015 \\
\hline Confined masonry wall system made with hollow units and without horizontal steel reinforcement (joint reinforcement or wire mesh) & 0.0015 \\
\hline Unreinforced and unconfined masonry wall systems & 0.001 \\
\hline
\end{tabular}

20 years or after an earthquake equal or greater to $\mathrm{MCE}$ considered in MOC-2012 strikes the area where the baseisolated structure is located.

An important modification of MOC-2012 with respect to US guidelines is found in the section entitled "Testing of similar units", where the following is established:

Prototype tests are not required for isolators of the same type, material and dimensional characteristics to those that will be used for construction if:

1. The isolation unit has been previously tested using the specified sequence of tests, and this testing is completely documented or,

2. According to the Responsible for Structural Safety and a team of certified experts (peer review panel) named by the Building Official Authority, the manufacturer has previously conducted prototype tests for other projects using a similar or equivalent sequence of tests, and this testing is completely documented.

For both options, it is mandatory that the Building Official Authority will hire a team of certified experts (peer review panel) in experimental testing, theory and design of base-isolated structures, independent from the team in charge of the design project, in order to have enough technical arguments to: (a) approve that prototype tests are not required or, (b) request the mandatory prototype tests.
Item two and the last paragraph are included taking into account the opinion of some US experts that are not satisfied with current US guidelines in this regard. For example, Kelly [62] states that it is precisely the overregulation of the prototype testing advocated by the US guidelines on seismic isolation before the construction of the base-isolated structure the one responsible to make this technology unnecessarily unaffordable to most projects, therefore, limiting its application for the design and retrofit of buildings in the United States.

\section{CONCLUDING REMARKS}

This paper summarized the most relevant aspects of the new chapter for the seismic design of base-isolated structures in the Manual for Civil Structures (MOC-2012), a model design code in Mexico, and its relations to US guidelines and research efforts conducted in Mexico and worldwide to improve the seismic design of base-isolated structures. The proposed guidelines follow the general seismic design philosophy behind MOC-2008, but include several recommendations available for base-isolated structures in US guidelines as well as original recommendations based on research studies conducted in Mexico and worldwide.

Displacement design spectra are obtained indirectly from acceleration design spectra, but the difference with other international guidelines is that the maximum spectral displacement converges to the peak ground displacement when the period tends to infinity $(T \rightarrow \infty)$. This fact is an important improvement in MOC-2012 with respect to most inter- 
national codes, where due to the definition of the descending branch of the acceleration spectrum for long periods, displacements grew up irrationally for long periods.

Another relevant aspect in the definition of the design spectra of MOC-2012 is that it is recognized that reductions due to supplemental damping are not constant and they depend on the period and the characteristics of the ground motions, which constitutes a difference from the constant values proposed in US guidelines.

Reductions are allowed in the acceleration design spectra for the design of the structure above the isolation system to account for overstrength and redundancy in terms of a seismic reduction factor for base-isolated structures $\left(Q_{a s}^{\prime}\right)$ in a more transparent manner than what is currently proposed in other international guidelines. The overstrength factor depends primarily on the structural system, whereas the redundancy factor accounts primarily for how many lines of defense a building has in a given direction of interest. Then, the seismic reduction factor for base-isolated structures $\left(Q_{a s}^{\prime}\right)$ is defined in function of the overstrength and redundancy factors and the $T_{a s} / T_{E}$ ratio, allowing higher reductions for structures where the effective base-isolated fundamental period $T_{a s}$ is considerably higher than its corresponding fixed-base period $T_{E}$. Also, $Q_{a s}^{\prime}$ has to be reduced if the structure is found irregular according to MOC-2012 guidelines.

The design for the superstructure of base-isolated buildings with structural irregularities follows the general guidelines of MOC-2008 for the design of conventional buildings, which were reviewed and updated. However, new provisions were derived from original research on the torsional response for base-isolated structures. In particular, the definition of strong structural irregularities in terms of computed static eccentricities in the superstructure and/or the isolation system were based on parametric studies devoted to define these parameters.

A simplified method for the seismic design of low-rise, base-isolated shear wall structures is proposed in MOC2012. This simplified method is basically a hybrid method, where the design of the isolation system is a simpler but more restrictive version for the static method for baseisolated structures available in US guidelines and the design of the superstructure essentially is the improved simplified method for the seismic design of lowrise shear wall structures of Mexican seismic codes.

The static and dynamic methods of analysis mostly coincide with what it is proposed in US guidelines. However, there are some differences worth noting, particularly how torsional response and orthogonal effects, including the action of the vertical component of the ground motion, is accounted for design purposes. The proposal for the vertical distribution of forces in the superstructure in the static method is also somewhat different to what is available in US guidelines.

The review of the drift limits for the service earthquake and the MCE for base isolated structures in MOC-2012 is different to what is proposed in US guidelines. The proposed limiting values for the MCE are based on research studies conducted in Mexico for the most common structural systems used within the country.

Specialized sections related to the requirements, design, construction, required testing and review for the isolation system are entirely based on US guidelines. However, there are some small modifications that were done to make the base-isolated guidelines coherent as well as compatible with all regulations adopted by MOC-2012. A mandatory certificate of structural safety is required by MOC-2012, based on periodical inspections of the base-isolated structure. An important modification in the writing of the section entitled "Testing of similar units" was done in order to avoid overregulation on the initially required prototype testing for the base-isolation project that may inhibit the application of base isolation for the design and retrofit of buildings in Mexico.

As a result, the guidelines for the seismic design of baseisolated structures in MOC-2012 have a modern format. Extensive commentaries to these recommendations are provided within the document, with graphic illustrations and indepth detailed references to the research studies that were consulted for. It is also recognized in the commentaries that seismic codes should continuously evolve, so there is always room for improvement.

It is hoped that these new guidelines in MOC-2012 will help promote the use of base isolation in regions of high seismic hazard in Mexico, thus improving their seismic safety.

\section{ACKNOWLEDGEMENTS}

The financial support of Comisión Federal de Electricidad (CFE) through a research grant to Instituto de Ingeniería, UNAM, and the Fulbright-García Robles program for researchers, are gratefully acknowledged. Luis Eduardo PérezRocha and Javier Avilés are thanked for their invaluable input and exchange of ideas related to the definition of the elastic design spectra. Sonia Ruiz and Luis Eduardo PérezRocha are thanked for their valuable input for the final general equation for the supplemental damping factor $\beta$. Farzad Naeim is thanked for the exchange of ideas and sharing of information about the background of some recommendations available in US guidelines. The additional comments and suggestions of anonymous reviewers of the manuscript were very helpful to improve this paper and are gratefully acknowledged.

\section{REFERENCES}

[1] MOC-2008, "Manual de diseño de obras civiles. Diseño por sismo," in Comisión Federal de Electricidad, México, 2009 (in Spanish)

[2] A. Tena-Colunga, U. Mena-Hernández, L. E. Pérez-Rocha, J. Avilés, M. Ordaz and J. I. Vilar, "Updated seismic design guidelines for buildings of a model code of Mexico," Earthquake Spectra, vol. 25 , no. 4, pp. 869-898.

[3] MOC-2012, "Manual de diseño de obras civiles. Tema 3, Capítulo 2 , Diseño de estructuras con aislamiento de base. Recomendaciones y Comentarios," in Comisión Federal de Electricidad, México (in editing press process), 2012 (in Spanish) 
[4] A. Tena-Colunga, "Propuesta de lineamientos para el diseño por sismo de estructuras con aislamiento de base. Fundamentos," in Reporte de Investigación 449, División de Ciencias Básicas e Ingeniería, Universidad Autónoma Metropolitana, (in Spanish)

[5] A. Tena-Colunga, "Development of guidelines for the seismic design of base isolated structures in Mexico," in Proceedings, 9th World Seminar on Seismic Isolation, Energy Dissipation and Active Control of Structures, Kobe, Japan, CD-ROM, pp. 81-105, June, 2005.

[6] A. Tena-Colunga, "International seismic zone tabulation proposed by the 1997 UBC code: observations for Mexico," Earthquake Spectra, vol. 15, no. 2, pp. 331-360, 1999.

[7] A. Tena-Colunga, "Some retrofit options for the seismic upgrading of old low-rise school buildings in Mexico," Earthquake Spectra, vol. 12 , no. 4, pp. 883-902, 1996.

[8] R. González and F. J. Noguez, "Respuesta teórica de un edificio con aislamiento de base," Revista de Ingeniería Sísmica, no. 46, pp. 23-52, 1994.

[9] ASCE-7, "Minimum design loads for buildings and other structures," in ASCE Standard ASCE/SEI 7-10, American Society of Civil Engineers, 2010.

[10] IBC, “International Building Code, 2012 ed.”, in International Code Council, 2012

[11] S. E. Ruiz, J. P. H. Toxqui and J. L. Rivera, "Design spectra reduction coefficients for systems with seismic energy dissipating devices located on firm ground," in Proceedings, $14^{\text {th }}$ World Conference on Earthquake Engineering, Beijing, China, Paper 05-060036, CDROM, October, 2008

[12] Y. Y. Lin, and K. C. Chang, "Study on damping reduction factor for buildings under earthquake ground motions," Journal of Structural Engineering (ASCE), vol. 129, no. 2, pp. 206-214, 2003.

[13] J. J. Boomer, and R. Mendis, "Scaling of spectral displacement ordinates with damping ratios," Earthquake Engineering and Structural Dynamics, vol. 34, pp. 145-165, 2005.

[14] Y. Y. Lin, "Statistical study on damping modification factors adopted in Taiwan's seismic isolation design code by using the 21 September 1999 Chi-Chi earthquake, Taiwan," Engineering Structures, vol. 29, pp. 682-693, 2007.

[15] Cardone D., M. Dolce and M. Rivelli, "Evaluation of reduction factors for high-damping design response spectra," Bulletin of Earthquake Engineering, vol. 7, pp. 273-291, 2009.

[16] G. D. Hatzigeorgiou, "Damping modification factors for SDOF systems subjected to near-fault, far-fault and artificial earthquakes," Earthquake Engineering and Structural Dynamics, vol. 39, pp.1239-1258, 2010.

[17] C. E. Seguín, "Torsión en sistemas aislados sísmicamente con dispositivos elastoméricos," Ph.D. Thesis, Escuela de Ingeniería, Pontificia Universidad Católica de Chile, December, 2007 (in Spanish)

[18] "Base mexicana de datos de sismos fuertes, volumen 2," in Sociedad Mexicana de Ingeniería Sísmica, CD-ROM, December, 2000.

[19] L. E. Pérez-Rocha and M. Ordaz, "Maxima earthquakes for seismic design of structures," in Proceedings, 14th World Conference on Earthquake Engineering, Beijing, China, Paper 03-01-0030, CDROM, October, 2008.

[20] UBC, "Uniform Building Code, 1997 edition," in International Conference of Building Officials, Whittier, California, Vol. 2, 1997.

[21] FEMA-450, "NEHRP recommended provisions for seismic regulations for new buildings and other structures. Part 1: Provisions," in FEMA Publication 450, Federal Emergency Management Agency, Washington, DC, 2004.

[22] A. Tena-Colunga, H. Correa-Arizmendi, J. L. Luna-Arroyo and G. Gatica-Avilés, "Seismic behavior of code-designed medium rise special moment-resisting frame RC buildings in soft soils of Mexico City," Engineering Structures, vol. 30, no. 12, pp. 3681-3707, 2008.

[23] A. Tena-Colunga, "Seismic response of code-designed mediumrise slender, moment-resisting frame steel buildings in soft soils," in Proceedings, 9th US National and 10th Canadian Conference on Earthquake Engineering, Reaching Beyond Borders, Toronto, Canada, Paper No. 309, CD-ROM, July, 2010.

[24] E. A. Godínez-Domínguez and A. Tena-Colunga, "Nonlinear behavior of code-designed reinforced concrete concentric braced frames under lateral loading," Engineering Structures, vol. 32, pp. 944-963.

[25] E. Tapia-Hernández and A. Tena-Colunga, "Factores de ductilidad y sobrerresistencia en marcos de acero con contraventeo chevrón," Revista de Ingeniería Sísmica, no. 84, pp. 47-68, 2011.

[26] R. S. Jangid and T. K. Datta, "Seismic response of torsionally coupled structures with elastoplastic base isolation," Engineering Structures, vol. 16, no. 4, pp. 256-262, 1994.

[27] R. I. Skinner, W. H. Robinson and G. H. Mc Verry, An Introduction to Seismic Isolation, England: John Wiley and Sons, 1993.

[28] A. Tena, A., C. Gómez, J. M. Jara, R. González, A. Muñoz and J. L. Álvarez, "Estudio analítico de la respuesta sísmica de edificios con aisladores de base," in Report FJBS/CIS-95/09, Centro de Investigación Sísmica, AC, Fundación Javier Barros Sierra, Mexico City, June, 1995 (in Spanish).

[29] A. Tena, L. A. A. Gómez and M. Salazar, "Criterios de diseño y reglamentación de estructuras con aisladores de base para la costa del Pacífico," in Report FJBS/CIS-97/17, Centro de Investigación Sísmica, AC, Fundación Javier Barros Sierra, Mexico City, October, 1997 (in Spanish).

[30] J. L. Escamilla, "Respuesta torsional de aisladores sísmicos debida a excentricidades de los centros de rigidez de la superestructura,' MSc. Thesis, Sección de Estudios de Posgrado e Investigación, Escuela Superior de Ingeniería y Arquitectura, Instituto Politécnico Nacional Unidad Zacatenco, April, 2005 (in Spanish).

[31] A. Tena-Colunga and J. L. Escamilla-Cruz, "Torsional amplifications in asymmetric base-isolated structures," Engineering Structures, vol. 29, no. 2, pp. 237-247, 2007.

[32] F. Naeim and J. M. Kelly, Design of Seismic Isolated Structures, New York: John Wiley \& Sons, 1999.

[33] A. Tena-Colunga, "Some retrofit options for the seismic upgrading of old low-rise school buildings in Mexico," Earthquake Spectra, vol. 12, no. 4, pp. 883-902, 1996.

[34] D. M. Lee, "Base isolation for torsion reduction in asymmetric structures under earthquake loading," Earthquake Engineering and Structural Dynamics, vol. 8, pp. 349-359, 1980.

[35] M. Eisenberger and A. Rutenberg, "Seismic base isolation of asymmetric shear buildings," Engineering Structures, vol. 8, no. 1, pp. 2-9, 1986.

[36] S. Nagarajaiah, A. M. Reinhorn and M. C. Constantinou, "Torsion in base isolated structures with elastomeric isolation systems," ASCE Journal of Structural Engineering, vol. 119, no. 10, pp. 2932-2951, 1993.

[37] A. Tena-Colunga and C. Zambrana-Rojas, "Dynamic torsional amplifications of base-isolated structures with an eccentric isolation system," Engineering Structures, vol. 28, no. 1, pp. 72-83, 2006.

[38] A. Tena-Colunga and L. A. Gómez-Soberón, "Torsional response of base-isolated structures due to asymmetries in the superstructure,”Engineering Structures, vol. 24, no. 12, pp. 1587-1599, 2002.

[39] J. L. Almazán and J. C. de la Llera, "Lateral torsional coupling in structures isolated with the frictional pendulum system," in Proceedings, 12th World Conference on Earthquake Engineering, Auckland, New Zealand, Paper 1536, CD-ROM, 2000.

[40] R. S. Jangid and T. K. Datta, "Nonlinear response of torsionally coupled base isolated structure," ASCE Journal of Structural Engineering, vol. 120, no. 1, pp. 1-22, 1994

[41] S. Nagarajaiah, A. M. Reinhorn and M. C. Constantinou, "Torsional coupling in sliding base-isolated structures," ASCE Journal of Structural Engineering, vol. 119, no.1, pp. 130-149, 1993.

[42] K. L. Ryan and A. K. Chopra, "Estimation of seismic demands on isolators in asymmetric buildings using non-linear analysis," Earthquake Engineering and Structural Dynamics, vol. 33, pp. 395-418, 2004.

[43] V. Kilar and D. Koren, "Seismic behaviour of asymmetric base isolated structures with various distributions of isolators," Engineering Structures, vol. 31, no. 4, pp. 910-921, 2009.

[44] V. I. Matsagar and R. S. Jangid, "Impact response of torsionally coupled base-isolated structures," Journal of Vibration and Control, vol. 16, no. 11, pp. 1623-1649, 2010.

[45] A. Tena-Colunga, C. Gómez-Soberón and A. Muñoz-Loustaunau, "Seismic isolation of buildings subjected to typical subduction earthquake motions for the Mexican Pacific Coast," Earthquake Spectra, vol. 13, no. 3, pp. 505-532, 1997

[46] O. Villegas-Jiménez and A. Tena-Colunga, "Dynamic design procedure for the design of base isolated structures located on the 
Mexican Pacific Coast," in Proceedings, 12th World Conference on Earthquake Engineering, Auckland, New Zealand, Paper No. 929, February, 2000.

[47] A. Tena-Colunga and J. Cano-Licona, "Simplified method for the seismic analysis of masonry shear-wall buildings," ASCE Journal of Structural Engineering, vol. 136, no. 5, pp. 511-520, 2010.

[48] A. Tena-Colunga and A. López-Blancas, "Allowable torsional eccentricity for the simplified method for the seismic analysis of confined masonry shear-wall buildings," The Open Civil Engineering Journal, vol. 5, pp. 132-142, 2011.

[49] MOC-2012b, "Manual de diseño de obras civiles. Tema 3, Capítulo 2, Diseño de estructuras con aislamiento de base. Ayudas de diseño," in Comisión Federal de Electricidad, México (in editing press process), 2012. (in Spanish)

[50] A. Tena-Colunga, "Seismic design of base-isolated buildings in Mexico. Part 2: simplified method for the design of low-rise, shear wall buildings," companion paper accepted for publication in Open Civil Engineering Journal, 2012.

[51] J. M. Kelly, Earthquake-resistant design with rubber, NewYork: Springer-Verlang, 1993.

[52] A. Tena-Colunga and M. A. Pérez-Osornio, "Design displacements for base isolators considering bidirectional seismic effects," Earthquake Spectra, vol. 22, no. 3, pp. 803-825, 2006.

[53] T. Perea and L. Esteva, "Componente vertical de registros sísmicos en México y su efecto en la respuesta sísmica no lineal de edificios," Revista de Ingeniería Sísmica, no. 72, pp. 45-79, 2005. (in Spanish).

[54] A. Tena-Colunga, "Seismic design of base-isolated structures using capacity spectra," Journal of Earthquake Engineering, vol. 6, no. 4, pp. 553-586, 2002.
[55] S. M. Alcocer and R. Meli, "Test program on the seismic behavior of confined masonry structures," The Masonry Society Journal, vol. 13 , no. 2 , pp. $68-76,1995$.

[56] S. M. Alcocer, "Implications derived from recent research in Mexico on confined masonry structures", in Proceedings, CCMS Symposium, American Society of Civil Engineers, Chicago, pp. 82-92, 1996

[57] G. Aguilar, R. Meli, R. Diaz and R. S. Vazquez-del-Mercado, "Influence of the horizontal reinforcement on the behavior of confined masonry walls," in Proceedings, 11th World Conference on Earthquake Engineering, Acapulco, Mexico, Paper No. 1380, CDROM, 1996.

[58] S. M. Alcocer and J. A. Zepeda, "Behavior of multi-perforated clay brick walls under earthquake-type loading," in Proceedings, Eighth North American Masonry Conference, Austin, Texas, EUA, June, CDROM, 1999.

[59] S. M. Alcocer, J. Cesín, L. E. Flores, O. Hernández, R. Meli, A. Tena-Colunga and D. Vasconcelos, "The new Mexico City Building Code requirements for design and construction of masonry structures," in Proceedings, Ninth North American Masonry Conference, Clemson, South Carolina, CD-ROM, 656-667, June, 2003.

[60] S. M. Alcocer, J. G. Arias and A. Vázquez, "Response assessment of Mexican confined masonry structures through shaking table tests," in Proceedings, 13th World Conference on Earthquake Engineering, Vancouver, Canada, Paper No. 2130, CDROM, 2004.

[61] A. Tena-Colunga, A. Juárez-Ángeles and V. M. Salinas-Vallejo, "Cyclic behavior of combined and confined masonry walls," Engineering Structures, vol. 31, no. 1, pp. 240-259, 2009.

[62] J. M. Kelly, "Recent development in seismic isolation in the United States," Revista de Ingeniería Sísmica, no. 61, pp. 57-72, 1999.

This is an open access article licensed under the terms of the Creative Commons Attribution Non-Commercial License (http://creativecommons.org/licenses/ by-nc/3.0/) which permits unrestricted, non-commercial use, distribution and reproduction in any medium, provided the work is properly cited. 